NEWSLETTTER

Tina Marvasti, MS $\boldsymbol{c}^{1}$

Adam Pietrobon, BS $\mathrm{c}^{2}$

${ }^{1}$ Faculty of Medicine, University of Toronto, Toronto, ON

2 Faculty of Medicine, University of Ottawa, Ottawa, ON

\section{Newsletter Spring 2020: \\ Clinician Investigator Trainee Association of Canada (CITAC)}

Message from Tina Marvasti, President of the Clinician Investigator Trainee Association of Canada: National and international collaborations and evidence based advocacy for the Canadian $\mathrm{MD} / \mathrm{PhD}$ and $\mathrm{MD}+$ trainees

The overarching goals of the Clinician Investigator Trainee Association of Canada (CITAC) for 2020 are to expand its reach to increase membership and to continue to build strong relationships with our national and international partners. These goals will be achieved by applying the following three strategies:

1. Continue to develop and strengthen our relationships with national and international key partners and with stake holders

2. Better understand the needs of clinician-scientist trainees for evidence-based advocacy

3. Increase membership, improve communication with all members and highlight the accomplishments of trainees

\section{Correspondence to:}

Tina Marvasti

Email: tina.bineshmarvasti@mail.utoronto.ca 


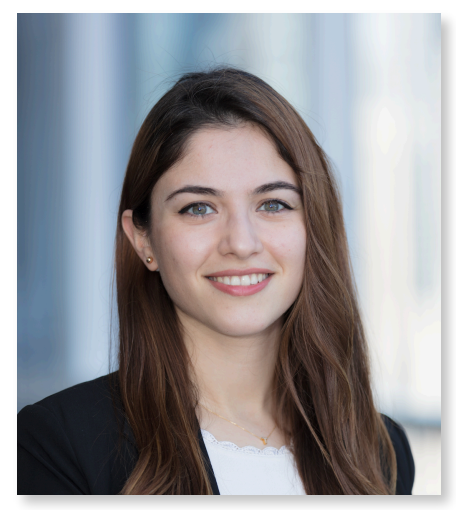

\section{Message from Tina Marvasti, President of the Clinician Investigator Trainee Association of Canada: National and international collaborations and evidence based advocacy for the Canadian MD/ $\mathrm{PhD}$ and MD+ trainees}

The overarching goals of the Clinician Investigator Trainee Association of Canada (CITAC) for 2020 are to expand its reach to increase membership and to continue to build strong relationships with our national and international partners. These goals will be achieved by applying the following three strategies:

\section{Continue to develop and strengthen our relationships with national and international key partners and with stake holders}

We are connecting with the Canadian Society for Clinical Investigation (CSCI) and the American Physician Scientists Association (APSA) with the goal of increasing collaborations and partnerships with our North American colleagues. We are also involved with the recent formation of the International Consortium of Clinician Scientist Trainee Organizations (ICCSTO), where MD+ trainees across the world will be learning about opportunities all around the globe. Furthermore, we will continue working with the Canadian Institutes for Health Research (CIHR) and the Association of Faculties of Medicine of Canada
(AFMC) to advocate for clinician-scientist training support in Canada.

2. Better understand the needs of clinician-scientist trainees for evidence-based advocacy

We will be launching several key surveys to gather information that will inform and strengthen our advocacy efforts. Our MD-PhD post-training consideration study is in its final stages and is ready for dissemination. We will share this information, alongside resources and information booklets, to the membership to help them guide their career planning.

\section{Increase membership, improve communication with all members and highlight the accomplishments of trainees}

To keep the general members engaged and aware of our advocacy and educational initiatives, this year we will improve our communication by publishing more frequent updates, which we will disseminate via e-mail and social media platforms. We will also continue to highlight the accomplishments of our trainees to raise awareness of their talents and potential. This will be done through our Twitter and Instagram platforms (@CITAC_ACCFC). Our goal is to increase the visibility of our organization and its members to attract the attention of international clinicianscientist trainees and faculties.

I look forward to sharing our progress with you in the coming year.

Sincerely, Tina B. Marvasti, MSc

MD-PhD student, University of Toronto

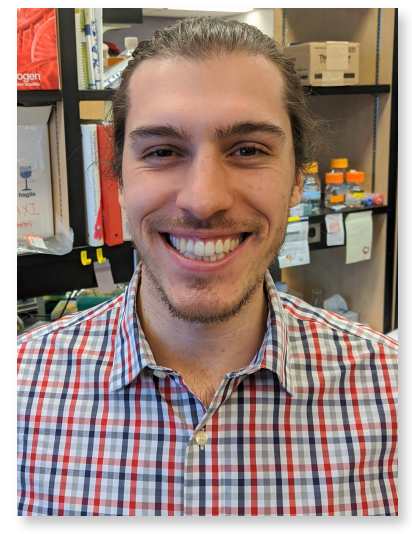

Message from Adam Pietrobon, president-elect: Many MD-PhD trainees are heavily considering completing post degree training internationally

This past year, CITAC sought to better understand clinicianscientist trainee considerations post-MD/PhD. On this topic, we distributed a survey mid-2019 to the general membership with an emphasis on characterizing intentions of pursuing international training. We received responses from every school that has an active clinician-scientist training program, with a total of
191 responses $(128 \mathrm{MD} / \mathrm{PhD}$ trainees and 63 Clinical Investigator Program participants). While formal release of these data is still in progress, we wanted to share with you some of the preliminary findings.

The majority $(69.5 \%)$ of $\mathrm{MD} / \mathrm{PhD}$ trainees are considering completing post- $\mathrm{MD} / \mathrm{PhD}$ training outside of Canada. Importantly, most of these trainees intend to ultimately pursue a clinician-scientist career in Canada. The most common reasons for considering post- $\mathrm{MD} / \mathrm{PhD}$ training outside of Canada include those related to prestige, productivity and specialized skills acquisition; trainees commonly perceive international training as an asset for their career prospects back in Canada. In contrast, personal and ethical reasons were the most common for considering staying in Canada for post-MD/PhD training. While not the 
most common, better integrated research-clinical training and improved funding sources were the most important reasons for considering training outside Canada. On a related note, the highest priority structural changes desired by clinicianscientist trainees were 1) improved research-clinical integration during residency and 2) clinician-scientist funding throughout the training continuum. Based on these data and ongoing trainee feedback, CITAC is bolstering its efforts to advocate for enhanced research integration during residency training (e.g., distinguished residency tracks and salary awards for clinician-scientist trainees). In parallel, in response to the widespread desire to train internationally, CITAC is developing resources to ensure trainees have the information needed for future career planning.

We welcome all insights on how to move forward, and would encourage anyone in the general membership to get in touch with us. In addition, if you are interested in reviewing your school-specific data, we would be happy to share that information (providing there was a sufficient response rate to guarantee anonymity).

\section{CITAC leadership 2020}

President — Tina B. Marvasti
President Elect - Adam Pietrobon
CITAC VP External — Bahar Behrouzi
CITAC VP External Elect — Sophie Hu
CITAC VP Internal — Valera Castanov
CITAC VP Internal Elect - Ellen Zhou
CITAC Secretary — Mark Trinder
CITAC Treasurer - Joel Neves Briard
CITAC Policy Chair - Andy Zeng
CITAC CIP Chair - Ali Fatehi Hassanabad
CITAC PR Chair — Jillian Macklin
CITAC Mentorship Chair — Julieta Lazarte
CITAC Membership Chair — Heather Whittaker
CITAC AGM Chair - Anum Rahman
CITAC AGM Chair — Sivakami Mylvaganam
CITAC CIM Liaison - Christopher Balestrini
CITAC CFMS Liaison - Cory Lefebvre
CITAC Finance Chair — Matthaeus Ware

Financial literacy and Canadian doctors-intraining

Adapted from MD Financial Management online article (https://
invested.mdm.ca/ md-articles/three-key-findings-about-financial-
literacy-and-canadian-doctors-in-training)

A new study commissioned by MD Financial Management (MDFM) about medical residents and financial literacy suggests most residents in Canada do not feel well-educated about their personal finances. In fact, many report having a lack of knowledge and confidence in their skills when it comes to making financial decisions. Many noted an absence of trust and clarity about who to turn to for assistance, with many saying they seldom use financial advisors.

In partnership with Environics Research, MDFM polled medical residents across Canada. Along with questions about financial priorities and goals, we quizzed respondents in order to assess their financial literacy.

This article discusses key areas of the study and how medical residents can better position themselves to gain greater financial control.

\section{Barriers to financial literacy leave budding doctors in the dark}

One of the biggest revelations from the study is that residents do not have a great handle on financial literacy, nor do they have the time to gain new financial wisdom. Medical residents averaged $53 \%$ on the MDFM financial literacy quiz.

Our study also discovered that $43 \%$ of resident respondents wish they knew more about investing. What stands in their way? Interestingly, $43 \%$ of residents said they do not have enough time, while $47 \%$ said they worried they do not know enough to be able to trust financial advisors.

MDFM insight: Medical residents seem to be stuck in a "catch-22". We know that going through a residency program is all-consuming; leaving very little available for anything else. For those who are short on time but want to learn more about investments and financial planning, MDFM provides convenient access to advisors that specialize in early career physicians by phone, in person or by Skype.

\section{Medical school expenses become less important with time}

Nearly seven of 10 medical residents reported feeling stressed when making decisions about financial priorities. While paying for school and loan repayment is naturally top 
of mind for medical students, MDFM sees these concerns lessen with age: $72 \%$ of residents reported worrying about loan repayment but for established physicians, schoolrelated expenses sat near the bottom of concerns.

As physicians age and gain more experience, the concern over academic expenses is slowly replaced by other interests: mortgages; children's educations; retirement; and so on. This change speaks to the impermanence of education-related debt over the course of a physician's career.

MDFM insight: Medical school debt can seem unwieldy to manage and it can be difficult to make other financial plans when you are busy paying it down. However, MD Advisors can help with a variety of services, including budgeting and expense management, to provide peace of mind that the debt you accumulate can be paid off with the personalized strategy you and your MD Advisor create together.

"Often when they are transitioning from residency to practice, they seek advice from our advisors who specialize in early career doctors to discuss paying off debt, starting to invest and practice incorporation," says Mary Ruddock, Wealth Planning and Strategy Lead at MD.

That's the perfect time to come up with a solid financial plan.

\section{Valuing balance between lifestyle and future needs}

One thing that remains fairly constant across respondents is the quest for present-future balance. This speaks to managing current expenses and lifestyle costs while also preparing for the future. Almost all of the study's respondents $(92 \%)$ said that striking this balance was important.

MDFM insight: The commonality of this priority suggests that all physicians at nearly every career stage values a good lifestyle and is willing to allocate a certain budget to living well. However, they have many competing priorities that change as they get older. Creating a budget and sticking to it can help keep lifestyle-related expenses in check while also fulfilling other financial needs. 